\title{
FINANCIAMENTO DA EDUCAÇÃO E AS IMPLICAÇÕES À GARANTIA DO DIREITO E QUALIDADE DA EDUCAÇÃO'1
}

\author{
Eraldo Souza do Carmo²
}

\begin{abstract}
Resumo
Este artigo tem a finalidade de analisar as implicações da estrutura de financiamento da educação à garantia do direito a educação. Problematizam-se as bases de cálculo para a distribuição de recursos da educação que ainda não são suficientes para superar as desigualdades educacionais regionais, principalmente dos municípios com pouca capacidade de arrecadação. As análises têm como base uma revisão teórica e a legislação educacional no que se refere às bases de financiamento da educação. Denota-se que as estratégias dos governos com a criação dos fundos para realizar a distribuição dos recursos da educação não contribuíram para elevar a qualidade da oferta educacional como tem sido propagado.
\end{abstract}

Palavras chaves: Direito a Educação. Financiamento da educação. Políticas educacionais.

\section{LA FINANCIACIÓN DE LA EDUCACIÓN Y LAS IMPLICACIONES PARA GARANTIZAR EL DERECHO Y LA CALIDAD DE LA EDUCACIÓN \\ Resumen}

Este artículo tiene como objetivo analizar las implicaciones de la estructura de financiamiento de la educación para garantizar el derecho a la educación. Se problematizan las bases de cálculo para la distribución de los recursos educativos, que aún no son suficientes para superar las desigualdades educativas regionales, especialmente en municipios con poca capacidad recaudatoria. Los análisis se basan en una revisión teórica y normativa educativa en cuanto a las bases para el financiamiento de la educación. Se observa que las estrategias de los gobiernos con la creación de fondos para llevar a cabo la distribución de los recursos educativos no contribuyeron a elevar la calidad de la oferta educativa como se ha propagado.

Palabras clave: Derecho a la educación. Financiamiento de la educación. Políticas educativas.

\section{FINANCING EDUCATION AND THE IMPLICATIONS FOR GUARANTEING THE RIGHT AND QUALITY OF EDUCATION \\ Abstract:}

This article aims to analyze the implications of the education financing structure in order to guarantee the right to education. The calculation bases for the distribution of education resources are problematized, which are still not enough to overcome regional educational inequalities, especially in municipalities with little tax collection capacity. The analyzes are based on a theoretical review and educational legislation with regard to the bases for financing the education. It is noted that the strategies of governments with the creation of funds to carry out the distribution of education resources did not contribute to raising the quality of educational offer as it has been propagated.

Keywords: Right to Education. Education financing. Educational policies.

\footnotetext{
${ }^{1}$ Artigo recebido em 01/06/2020. Primeira avaliação em 14/06/2020. Segunda avaliação em 17/07/2020. Terceira avaliação em 10/08/2020. Aprovado em 03/09/2020. Publicado em 25/09/2020.

DOI: https://doi.org/10.22409/tn.v18i37.42969.

${ }^{2}$ Doutor em Educação pela Universidade Federal do Pará. Professor da Universidade Federal do Pará (Campus de Cametá), Pará / Brasil. E-mail: eraldo@ufpa.br ORCID: 0000-0003-4824-8016. Lattes: http://lattes.cnpq.br/4280135157998138.
} 


\section{Introdução}

O artigo busca problematizar a estrutura de financiamento da educação brasileira definida pela Constituição Federal (CF) de 1988 e, posteriormente, com a criação da política de Fundos enquanto estratégia do governo federal para corrigir as distorções nos recursos destinados à educação. Aspectos que não se tornaram tão eficazes, tendo em vista que essa política não representou recursos adicionas ou novas fontes de recursos à educação. Ainda que ocorra a complementação de recursos da União e as transferências complementares diretas aos municípios por meio de programas educacionais, esses não são, no entanto, recursos fixos nos caixas dos municípios.

Desta maneira, o financiamento da educação tem fomentado o debate das políticas educacionais nos últimos anos, tendo em vista assegurar o direito à educação, principalmente às populações em condições de vulnerabilidade social. Essas questões se refletiram na centralidade das discussões quando da aprovação do Plano Nacional de Educação (PNE), Lei no 13.000/2014, quanto ao investimento de $10 \%$ do PIB até o final do período a que se refere o plano (BRASIL, 2014).

Entretanto, discutir os aspectos e a estrutura de financiamento da educação brasileira requer compreender as responsabilidades da União, dos Estados, do Distrito Federal e dos Municípios com os processos educacionais. A LDB 9394/1996 assegura que cabe à União a coordenação da política nacional de educação, articulando os diferentes níveis e sistemas, além de ter função normativa, redistributiva e supletiva em relação às demais instâncias educacionais (§ 1ํ do Art. $8^{\circ}$ ) (BRASIL, 1996).

Dentre as funções da União é importante destacar que o art. 9o, inciso III, assegura que ela deve "prestar assistência técnica e financeira aos Estados, ao Distrito Federal e aos Municípios para o desenvolvimento de seus sistemas de ensino e o atendimento prioritário à escolaridade obrigatória, exercendo sua função redistributiva e supletiva" (BRASIL, 1996).

Essa forma de distribuição das competências pelos sistemas de ensino, conforme preconizou a LDB 9.394/1996, se reflete também na distribuição dos recursos e nas responsabilidades que asseguram o direito à educação para as populações. Entretanto, esse processo, segundo estudiosos da educação, expressa contradições. Para Castro (2011), ele representou avanço ao deixar expressas as responsabilidades de cada ente federado com o ensino, cabendo ao município a 
educação infantil, a educação básica, e a EJA. Esta responsabilidade municipal também é item de questionamento, ou seja, até que ponto os municípios conseguem responder de forma satisfatória às suas populações?

\section{A centralidade das políticas educacionais nos municípios e os recursos educacionais}

Discutir financiamento remete a pensar no conjunto de determinadas despesas, levando-se em conta a capacidade de poder financiá-las. Na educação, esse processo não é diferente e trata-se de uma política de direito social. Sendo assim, não se pode definir um beneficiário, já que todos o são.

É a partir dessa assertiva que situamos o debate do financiamento da educação, mecanismo principal de execução das políticas educacionais, que, em tese, devem garantir a efetivação do direito outorgado constitucionalmente. A educação, enquanto um direito de todos, deve ser assegurado pelo Estado e pela família, como define o artigo 205 da CF/1988. Neste aspecto, a colaboração da sociedade deve envidar esforços para que ela se efetive como direito, perpassando, inclusive, pelos aspectos financeiros. Esses esforços devem se dirigir ainda para o atendimento das condições de oferta da educação, descritas no artigo 206 da Constituição Federal de 1988, como expressam, a título de exemplo, os incisos I e VII: "igualdade de condições para o acesso e permanência na escola e garantia de padrão de qualidade". (BRASIL, 1988).

Dessa forma, para a garantia do direito à educação, os responsáveis pela oferta devem atentar-se para os diversos aspectos que abarcam os interesses do Estado, dos alunos, da sociedade e dos profissionais da educação, buscando valorizar tanto $o$ aspecto formativo quanto o salarial.

É importante reforçar que os gestores devem prover, em condições de igualdade, o acesso e a permanência dos alunos na escola, bem como a qualidade desse acesso e permanência baseados no princípio da qualidade, a fim de evitar as desigualdades, principalmente em um país como o Brasil, que possui dimensões continentais. A esse respeito, Sena (2014, p. 270) destaca que: "[...] a qualidade da educação integra o núcleo essencial do direito à educação, já que a garantia do padrão de qualidade é um princípio a partir do qual o ensino deve ser ministrado". Depreende-se, com isso, que o direito à educação não se encerra na garantia do 
acesso, mas estende-se à permanência, pois deve ser considerado o aspecto da qualidade enquanto obrigação constitucional, conforme está na CF/1988.

De forma legítima, o direito à educação, já inscrito na CF/1988, foi ratificado em outros termos jurídicos brasileiros, como no Estatuto da Criança e do Adolescente (ECA) - Lei no 8.069/1990 (BRASIL, 1990) e na LDB 9.394/1996 (BRASIL, 1996). No entanto, a garantia dos direitos nos marcos jurídicos, por si só, não é sinônimo da melhoria da qualidade na educação; é preciso, sim, um conjunto de políticas educacionais para que esses direitos sejam efetivados. Nessa mesma perspectiva, Rezende Pinto (2014, p. 42) destaca que:

[...] a declaração dos direitos sociais na Lei Maior brasileira, embora louvável e de suma importância, não foi suficiente para garantir a sua efetivação e, por conseguinte, para a concretização de uma sociedade mais livre, justa e solidária, como preconiza nossa carta constitucional.

A efetivação do direito à educação, como destaca a autora, ainda é um processo que está em disputa na sociedade, a fim de garantir condições de igualdade a todos os cidadãos. É importante destacar que a LDB (9.394/1996) está em plena sintonia com a CF/1988, no que concerne à garantia do direito à educação.

Apesar da importância desses marcos jurídicos, segundo Cruz (2011, p. 82), ainda são frágeis essas garantias do direito à educação tendo em vista que não garantem que os governos o efetivem, já que "as condições materiais que poderiam viabilizar a implementação do direito à educação ainda são muito genericamente definidas, principalmente frente à insuficiência de recursos para universalizar e qualificar a oferta educacional pública".

A referida LDB, em relação à educação pública, avança ao definir atribuições e responsabilidades aos entes federados com cada nível de ensino e ao promover a organização e a oferta da educação básica (BRASIL, 1996). Entretanto, segundo Cruz (2011), a distribuição das competências entre os entes federados pelo ensino teria um efeito inverso no regime de colaboração e compartilhamento das responsabilidades, dados os desníveis socioeconômicos regionais e intrarregionais. É compreensível a preocupação da autora, uma vez que, na divisão de competências dos níveis do ensino, coube aos municípios as maiores responsabilidades com a oferta, ou seja, são eles os responsáveis pela Educação Infantil e pelo Ensino Fundamental, além da Educação Especial e EJA, sendo o ente federado que mais garante essa oferta. 
A título de exemplo, o Censo Escolar de 2018 para a Educação Básica registrou um total de 48.455,867 (quarenta e oito milhões quatrocentos e cinquenta e cinco mil oitocentos e sessenta e sete) matrículas. Desse total, 47,7\%, estavam situadas nas redes municipais, $32,9 \%$ nas redes estaduais, $18,6 \%$ nas redes privadas e $1 \%$ na rede federal. (INEP, 2018).

Esses dados evidenciam o tamanho da responsabilidade que os municípios têm para com a oferta e a garantia do direito à educação. A propósito, eles têm atribuições obrigatórias, como a oferta de ensino para a população de 4 a 14 anos de idade, o que corresponde à Pré-Escola e ao Ensino Fundamental conforme art. 4º inciso I da LDB 9394/1996 (BRASIL, 1996).

A concentração de matrículas nas redes municipais acarreta muito mais responsabilidades e custos financeiros para esses entes. Com efeito, o ensino em creche, embora seja facultativo, é solicitado fortemente que seja ofertado nos estabelecimentos públicos atendendo a forte cobrança social. E os municípios tentam suprir também, embora em menor escala, a essa demanda social.

Do ponto de vista das demandas da sociedade, a mesma não está interessada em saber de quem é a responsabilidade de atendimento de seus direitos nem de onde provêm os recursos para atendê-los, ela apenas exige seus direitos, pois "[...] cada sociedade incorpora o reconhecimento de determinadas necessidades educacionais e que o Estado deva assumir certa responsabilidade de resposta" (CASTRO, 2007, p. $860)$.

Nesse sentido, tem recaído sobre os municípios uma cobrança maior da sociedade para com a oferta de ensino, a fim de garantir o direito à educação. Essa é a forma que tem pautado as relações dialéticas entre as iniciativas governamentais e os interesses sociais pela ampliação das políticas educacionais, para garantir o acesso de todos à escola, independentemente de ser obrigatória ou facultativa. Entretanto, não se efetiva um direito sem os recursos financeiros necessários para custear as políticas de acesso. Assim, as municipalidades, principalmente as das regiões Norte e Nordeste do país, se encontram impedidas de prover uma educação de qualidade (CRUZ, 2011).

Portanto, o modelo de federalismo do Estado brasileiro tem atribuído maiores responsabilidades educacionais aos municípios, sobretudo a partir da LDB 9.394/1996. A justificativa do governo central seria a de que os governos locais seriam mais eficientes no gerenciamento das políticas educacionais, mas, 
contraditoriamente, a descentralização se fez com base na centralização das definições das políticas educacionais e dos recursos financeiros (CRUZ, 2011).

Embora o repasse de recursos dos governos estaduais e da União para os municípios tenha sido crescente, a realidade demonstra que esse repasse não é suficiente. Isso, de certa forma, inviabilizou a autonomia dos munícipios para definirem suas políticas e cumprirem com as responsabilidades que lhes foram atribuídas.

\section{A base constitucional do financiamento da educação brasileira para assegurar o direito a educação}

O centro das discussões dos últimos anos está definido no que se refere a oferta de ensino, aliado à qualidade da educação. Esses são direitos assegurados pela CF/1988, expressos no artigo 206 (BRASIL, 1988), e também no artigo 4ํ da LDB 9394/1996 (BRASIL1996). Destaca-se ainda que o Novo PNE, Lei oㅜ 13.005, definiu como sua sétima meta fomentar a qualidade da Educação Básica em todas as etapas e modalidades de ensino (BRASIL, 2014).

Entretanto, para se alcançar essa premissa, é preciso entender o quanto os governos estão dispostos a investir no custo-aluno em suas diversas realidades para que a qualidade do ensino seja materializada e saia do nível das intencionalidades e dos planos. É conveniente compreender a estrutura de financiamento da educação na legislação brasileira, uma vez que são esses instrumentos que asseguram as receitas para a União, Estados e Municípios implementarem as políticas educacionais.

Nessa perspectiva, o marco estrutural do financiamento da política educacional brasileira, segundo Castro (2011), está constituído pela CF/1988, pelo ECA (Lei no 8.069/1990), pela LDB (Lei no 9.394/1996), pela EC oํ 14/1996, pela EC oㅜ53/2006 e a de $n^{\circ} 59 / 2009$, e por um conjunto de normas infraconstitucionais e resoluções do Conselho Nacional de Educação. Esse arcabouço jurídico fixa, de acordo com o autor, a atual estrutura de responsabilidades e competências para a oferta da educação no Brasil.

Para Castro (2011), ao menos a partir dos aspectos constitucionais, o direito básico à educação está bem definido para o atendimento à população. Entretanto, para além do que está assegurado na legalidade do direito, é preciso avançar no campo do debate, para que o Estado implante políticas que considerem a diversidade 
socioeconômica e a diversidade geográfica do Brasil, pois, assim, poderão ser reduzidas as desigualdades educacionais.

Em face disso, a CF/1988 estabeleceu responsabilidades dos entes federados para com o financiamento da educação, definindo os percentuais que devem aplicar na Manutenção e Desenvolvimento do Ensino (MDE). Dessa forma, o artigo 212 assegura que a União aplicará, anualmente, nunca menos de 18\% (dezoito por cento), enquanto que os Estados, o Distrito Federal e os Municípios, devem aplicar 25\% (vinte e cinco por cento), no mínimo, da receita resultante de impostos (BRASIL, 1988).

Ademais, a CF/1988 assegurou o salário-educação, proveniente do recolhimento da contribuição social das empresas, que complementa o financiamento

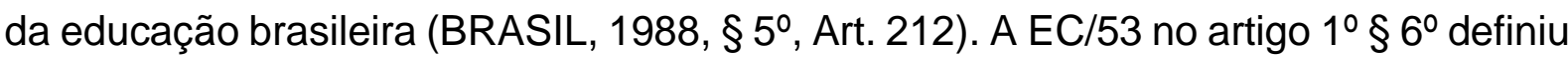
que "as cotas estaduais e municipais da arrecadação da contribuição social do salárioeducação serão distribuídas proporcionalmente ao número de alunos matriculados na educação básica nas respectivas redes públicas de ensino”. (BRASIL, 2006).

Essas prerrogativas asseguradas pela CF/1988 sobre o financiamento da educação foram, segundo Castro (2011), ratificadas pela LDB 9394/1996, em seu artigo 69, ao apontar a proveniência dos recursos para a manutenção e desenvolvimento do ensino público no país (BRASIL,1996). A fim de evidenciar a estrutura do financiamento da educação no Brasil e a proveniência das receitas dos entes federados, são apresentados dados no Quadro 1.

Observa-se nele, que a estrutura do financiamento da educação no país está, portanto, concentrada na captação de recursos por meio da vinculação de impostos de forma obrigatória da União, dos Estados e dos Municípios. Identificam-se, nesse mesmo quadro, os impostos vinculados à educação de cada ente federado, ou seja, os que geram receitas para a educação. Assim, há os federais, os estaduais e os municipais. Nessa estrutura tributária, os municípios saem em desvantagem, uma vez que o recolhimento de IPTU, ISS, ITBI vai oscilar muito de um município para outro, influenciando no quantitativo desequilibrado de recursos para a educação; assim como os impostos dos Estados também oscilam, refletindo em desigualdade no quantitativo de recursos de um estado para outro. 
Quadro 1 - Impostos e contribuições sociais arrecadados pela União, Estados, Distrito Federal e Munícipios, que geram recursos da educação, conforme percentuais definidos a serem aplicados em MDE

\begin{tabular}{|c|c|c|}
\hline União & Estados & Municípios \\
\hline $\begin{array}{l}1 \text { Orçamentários } \\
\text { (Tesouro Nacional) }\end{array}$ & $\begin{array}{l}\text { Orçamentários } \\
\text { (Tesouro Nacional) }\end{array}$ & $\begin{array}{c}\text { Orçamentários } \\
\text { (Tesouro Nacional) }\end{array}$ \\
\hline Ordinários do Tesouro & $\begin{array}{l}\text { Vinculação de receita de } \\
\text { impostos (25\%) para MDE }\end{array}$ & $\begin{array}{l}\text { Vinculação de receita de impostos } \\
(25 \%) \text { para MDE }\end{array}$ \\
\hline $\begin{array}{c}\text { Vinculação da receita } \\
\text { de impostos (18\%) para } \\
\text { MDE }\end{array}$ & ICMS - FUNDEB $(20 \%)=(5 \%)$ & IPTU \\
\hline (I.R) & IPVA- FUNDEB (20\%)=(5\%) & ISS \\
\hline (I.P.I) & ITCM - FUNDEB $(20 \%)=(5 \%)$ & ITB| \\
\hline \multirow{2}{*}{ (I.T.R) } & IRRF - FUNDEB $(20 \%)=(5 \%)$ & IRRF \\
\hline & Transferência & Transferência \\
\hline \multirow{2}{*}{ (I.O.F } & \multirow{2}{*}{ FPE - FUNDEB $(20 \%)=(5 \%)$} & FPM - FUNDEB $(20 \%)=(5 \%)$ \\
\hline & & IPI - EXP - FUNDEB (20\%)=(5\%) \\
\hline (I.I.) & IPI -EXP - FUNDEB $(20 \%)=(5 \%)$ & $\begin{array}{l}\text { ITR - FUNDEB }(20 \%)=(5 \%) \\
\text { IOF - FUNDEB }(20 \%)=(5 \%)\end{array}$ \\
\hline \multirow{2}{*}{ (I.E) } & \multirow{2}{*}{$\begin{array}{l}\text { Lei Kandir - FUNDEB } \\
(20 \%)=(5 \%)\end{array}$} & ICMS - FUNDEB $(20 \%)=(5 \%)$ \\
\hline & & IPVA - FUNDEB $(20 \%)=(5 \%)$ \\
\hline (I.G.F) & $\begin{array}{c}\text { Subvinculação do FUNDEB dos } \\
\text { Estados }\end{array}$ & Subvinculação do FUNDEB \\
\hline União & Estados & Municípios \\
\hline $\begin{array}{l}2 \text { Contribuições } \\
\text { Sociais }\end{array}$ & 2 Transferências & 2 Transferências \\
\hline $\begin{array}{l}\text { Salário-educação/cota } \\
\text { federal um terço }\end{array}$ & Salário-educação/cota federal & Salário-educação/cota estadual \\
\hline $\begin{array}{l}\text { Contribuição sobre o } \\
\text { lucro líquido }\end{array}$ & Orçamentários da União & Salário-educação/cota federal \\
\hline $\begin{array}{l}\text { Contribuição para a } \\
\text { seguridade social }\end{array}$ & \multirow{2}{*}{$\begin{array}{l}\text { Aplicação do salário } \\
\text { educação/cota federal e outras } \\
\text { fontes do FNDE }\end{array}$} & Salário-educação/cota municipal \\
\hline $\begin{array}{l}\text { Receitas brutas } \\
\text { (prognósticos) }\end{array}$ & & Orçamento do Estado \\
\hline 3 Mistos & 3 Contribuições sociais & 3 Orçamento da União \\
\hline $\begin{array}{l}\text { Fundo de Combate e } \\
\text { Erradicação da Pobreza }\end{array}$ & $\begin{array}{c}\text { Salário educação/cota estadual- } \\
\text { dois terços }\end{array}$ & $\begin{array}{l}\text { Aplicação do salário-educação/cota } \\
\text { federal e outras fontes FNDE }\end{array}$ \\
\hline 4 Outros & 4 Outros & 4 Outros \\
\hline Operações de crédito & & \\
\hline $\begin{array}{l}\text { Renda líquida da loteria } \\
\text { federal }\end{array}$ & Diretamente arrecadados & Diretamente arrecadados \\
\hline \multicolumn{3}{|l|}{ Renda de órgãos } \\
\hline $\begin{array}{l}\text { Aplicação do salário- } \\
\text { educação/cota federal e } \\
\text { outras fontes do FNDE }\end{array}$ & Operações de créditos & Operações de créditos \\
\hline $\begin{array}{l}\text { Diretamente } \\
\text { arrecadados }\end{array}$ & \multirow[t]{2}{*}{ Diversos } & \multirow[t]{2}{*}{ Diversos } \\
\hline Diversos & & \\
\hline
\end{tabular}

Fonte: Castro (2011), EC 14/2006. Material elaborado pelo autor. 
Esses recursos que compõem o fundo da educação são arrecadados, de acordo com Castro (2007, p. 858), "[...] de forma impositiva ao cidadão pelo Estado". O financiamento é misto e complexo, porém, a lógica da vinculação "é uma das medidas políticas mais importantes para garantir disponibilidade de recursos para o cumprimento do vasto rol de responsabilidades do poder público nesta área" (CASTRO, 2011, p. 32).

Ainda no quadro 01, observa-se que a partir das receitas dos impostos vinculados à educação são gerados os recursos que financiam as políticas educacionais dos entes federados. Cumpre esclarecer que os percentuais que se destinam aos financiamentos da educação atribuídos à União (18\%) e aos Estados (25\%) incidem sobre as receitas líquidas dos impostos, ou seja, é somente após realizarem as transferências aos demais entes que são aplicados os devidos percentuais.

Cumpre destacar também que os recursos para financiar a educação, assegurados em sua maioria na CF/1988, são provenientes do recolhimento dos impostos e complementados com as contribuições sociais das empresas, o salárioeducação. Entretanto, essa forma de calcular os recursos para a educação causa instabilidade financeira para os entes federados, uma vez que as receitas têm como termômetro o desempenho da economia do país.

Gouveia e Polena (2015, p. 256) reforçam essa ideia de que o desenho de financiamento da educação pública no Brasil, com base na vinculação de receitas dos impostos de diferentes entes federados, tem garantido uma relativa estabilidade aos investimentos em educação, mas também compreendem, da mesma forma, que "[...] em tempos de crescimento econômico, o investimento em educação cresce de forma quase inercial, como reflexo do aumento da arrecadação. O oposto acontece em contextos de crise, quando há queda na arrecadação".

Isso se reflete nos constantes cortes no orçamento para a área da educação, que vêm ocorrendo de forma exponencial em todos os governos nos momentos de crise econômica, sob o argumento de se fazer o ajuste fiscal. Para além desses aspectos, a partir do ano de 1996, teve início um novo processo de distribuição dos recursos da educação, o que não significou diminuição e nem tampouco acréscimo de novas receitas para a educação, pelos entes federados.

O marco regulatório, nesse contexto, foi a aprovação da EC nํ 14/1996, que criou o FUNDEF, regulamentado pela Lei nº 9.424/1996. A partir desse marco jurídico, 
$15 \%$ (quinze por cento) dos recursos dos impostos vinculados à educação passaram a ser subvinculados ao referido fundo de cada Estado e do Distrito Federal. Assim, cada ente estadual e mais o Distrito Federal passaram a ter um fundo constituído com parte de seus próprios recursos e com recursos oriundos dos municípios - desses, apenas os de transferência, como pode ser verificado no quadro 01 .

Como definiu a EC de № 14/1996, o fundo era de natureza contábil (sem estrutura administrativa), por isso, não representou novos recursos para a educação, pois apenas subvinculou recursos que, por direito, eram dos estados e municípios. Para Gemaque (2011), o fundo caracterizou-se como de gerenciamento e não de captação de novos recursos à educação.

Importa destacar que o artigo $2^{\circ}$ da Lei de № 9.424/1996 deixou explícito que "os recursos do Fundo deveriam ser aplicados na manutenção e desenvolvimento do ensino fundamental público, e na valorização de seu Magistério". Quanto à distribuição dos recursos entre o Estado e os municípios, ela deveria considerar a proporção do número de alunos matriculados anualmente nas escolas cadastradas, nas respectivas redes de ensino, por meio da realização do Censo Escolar, tomando como base de cálculo o valor aluno para as matrículas de ensino fundamental (BRASIL, 1996, $§ 1^{\circ}$ do Art. $\left.2^{\circ}\right)$.

Entretanto, a Lei do FUNDEF assegurou a diferenciação do valor por aluno, segundo os níveis de ensino e tipos de estabelecimento ( $\left(2^{\circ}\right.$ do Art. $\left.2^{\circ}\right)$. Dessa forma, os cálculos para a distribuição dos recursos do fundo deveriam considerar as matrículas de: $1^{\underline{a}}$ a $4^{\underline{a}}$ séries; $5^{\underline{a}}$ a $8^{\underline{a}}$ séries; estabelecimentos de ensino especial e escolas rurais (BRASIL, 1996). De outra forma, a EC o 14 assegurou no artigo 5ำ § $3^{\circ}$, que a União complementaria os recursos dos fundos, em cada Estado e no Distrito Federal, caso o valor por aluno não alcançasse o mínimo definido nacionalmente (BRASIL/EC, 1996).

Assim, deu-se início à política de fundo na estrutura educacional brasileira, em que, a partir da subvinculação dos recursos dos impostos (15\%), foram criadas novas estratégias de distribuição entre os estados, o distrito federal e municípios. Diante disso, a matrícula de cada rede de ensino passou a ser o indicador principal para mensurar os recursos que cada um dos Estados, municípios e o distrito federal receberiam do fundo. Gemaque (2011), ao refletir sobre a finalidade do FUNDEF destaca que esse fundo foi instituído com a perspectiva de que: 
[...] revolucionaria a educação ao promover justiça social, equidade nos gastos aluno, descentralização do ensino, redução das disparidades regionais. Configurou-se como uma política focalizada visto que priorizou exclusivamente uma etapa da educação básica - 0 Ensino Fundamental. Ancorou-se na lógica de que o problema central do financiamento da educação residia no seu gerenciamento, decorrente da incompatibilidade entre o atendimento às matrículas e a capacidade fiscal dos entes federados. Caracterizou-se, portanto, como um Fundo de gerenciamento e não de captação de novos recursos para financiar "novos" programas implementados no Ensino Fundamental, pois era constituído da subvinculação dos recursos já vinculados à educação. (GEMAQUE, 2011, p. 92).

Portanto, são esclarecedoras as explicações de Gemaque (2011) sobre as condições e justificativas governamentais em que foi instituída a política de fundos no sistema educacional brasileiro. Destaca-se a intenção do Estado brasileiro de pretender fazer uma revolução educacional, mas sem acréscimo de novas fontes de recursos para a educação. Criou-se uma política de financiamento sem recursos, apenas sobre as mesmas bases de financiamento da educação em vigor. Para tanto, o principal argumento do Estado foi o de que o problema da educação não estaria no aporte de mais recursos, mas sim no gerenciamento das cifras disponíveis (SHIROMA, 2000).

Embora o fundo tenha sido constituído pelos Estados e pelo Distrito Federal, que subvincularam as receitas dos seus impostos, manteve-se a relação desigual entre estados e regiões do país, considerando o desnível financeiro que existe entre essas federações. Essas desigualdades, para Gemaque (2011), ao final do FUNDEF, ainda eram evidentes, sobretudo quando os estados permaneceram com os mesmos valores per capita de renda, no ano de 2006, em relação a 1998. Como exemplo de menor per capita, citou o caso do Maranhão, e o de maior, o Estado do Acre - ambos se mantiveram em condições iguais ao final de 10 (dez) anos do FUNDEF.

À luz desses dados, Gemaque (2011) pontuou a contradição no argumento justificador da implementação do FUNDEF, que reduziria as disparidades entre custoaluno. Assim, enfatiza que se confirmou a previsão inicial de que esse fundo, nos moldes em que foi organizado, não diminuiria as disparidades regionais.

Por conseguinte, o FUNDEF, ao final de 2006, foi substituído por outro fundo, o Fundo de Manutenção e Desenvolvimento da Educação Básica e Valorização do Magistério (FUNDEB), que foi regulamentado por meio da Lei nº 11.494/2007, com previsão de funcionar até 2020. Diferencia-se do antigo fundo por atender toda a 
Educação Básica, porém, continua sendo de natureza contábil e constituído a partir da subvinculação dos impostos, mas ampliado em 20\%, como expõe o quadro 1.

Com uma situação análoga a do FUNDEF, os municípios só contribuem para o fundo com os percentuais dos impostos recebidos das transferências da União e dos Estados, que são deduzidos diretamente para o fundo. Portanto, as contribuições das taxas como IPTU, ISS entre outros impostos municipais ,estão isentos do fundo, mas não de serem destinadas aos respectivos percentuais de 25\% para a educação.

Conforme estabelecido no artigo 6ำ da Lei do FUNDEB, a União deve fazer complementação de $10 \%$ (dez por cento) do total dos recursos que constituem os fundos, sempre que, no âmbito de cada Estado e no Distrito Federal, o valor médio ponderado por aluno não alcançar o mínimo definido nacionalmente (BRASIL/FUNDEB, 2007).

Quanto à distribuição dos recursos do fundo, ela deve ser proporcional às matrículas efetivadas em cada rede educacional de responsabilidade obrigatória, considerando os resultados oficiais publicados pelo Censo Escolar de cada ano. Os cálculos devem ser realizados com base no valor/aluno, divulgado anualmente pelo FNDE, e devem considerar as diferenças entre etapas, modalidades e tipos de estabelecimento de ensino da Educação Básica, como define o artigo 10 da lei. ${ }^{3}$

Essa forma de realizar o cálculo para a distribuição dos recursos entre as redes de ensino representou um avanço em relação ao FUNDEF, uma vez que este considerava apenas os níveis de ensino e tipos de estabelecimento, urbano e rural. Logo, o FUNDEB, além de atender toda a Educação Básica, no cálculo valor aluno/ano passou a considerar não só a localização dos estabelecimentos de ensino (urbano e rural), mas também as etapas, as modalidades e os níveis de ensino atendidos com as respectivas matrículas. Essa equalização do valor gasto aluno/ano, tendo como referência o indicador de matrícula, foi considerada por Castro (2011) inovadora.

\footnotetext{
${ }^{3}$ I - creche em tempo integral; II - pré-escola em tempo integral; III - creche em tempo parcial; IV - préescola em tempo parcial; $\mathrm{V}$ - anos iniciais do ensino fundamental urbano; VI - anos iniciais do ensino fundamental no campo; VII - anos finais do ensino fundamental urbano; VIII - anos finais do ensino fundamental no campo; IX- ensino fundamental em tempo integral; X - ensino médio urbano; $\mathrm{XI}$ - ensino médio no campo; XII - ensino médio em tempo integral; XIII - ensino médio integrado à educação profissional; XIV - educação especial; XV - educação indígena e quilombola; XVI - educação de jovens e adultos com avaliação no processo; XVII - educação de jovens e adultos integrada à educação profissional de nível médio, com avaliação no processo. (BRASIL/FUNDEF, 2007).
} 
Assim, atualmente, no FUNDEB, o valor aluno/ano é calculado com base em 17 (dezessete) variáveis, conforme observado no artigo 10, enquanto, no FUNDEF, eram apenas 4 (quatro). Contudo, para Bremaeker (2011, p. 60), esses coeficientes foram decididos de maneira arbitrária, uma vez que foram "acordados" por representantes do MEC, dos estados e dos municípios. Em seu entendimento, "o estabelecimento de coeficientes únicos para todo o país fez parecer que o custo das modalidades de ensino seria o mesmo nos diferentes rincões da Amazônia e na cidade de São Paulo, no Nordeste ou no Sul do país.".

Os fatores de ponderação de custo-aluno assim definidos causaram, segundo Pinto (2007, p. 891), muitas controvérsias, tendo em vista que os critérios utilizados não abarcaram o custo real das etapas e modalidades de ensino. Com isso, reforçouse a tese de Bremaeker, para quem esse cálculo foi uma decisão política, que teve como parâmetro a busca de um acordo mínimo entre estados e municípios. Ainda conforme Pinto:

\begin{abstract}
A busca de um entendimento mínimo que garantisse a aprovação do fundo impediu, contudo, que fossem tomados como parâmetro, no seu primeiro ano de funcionamento, fatores de ponderação que explicitassem as diferenças reais de custo. Assim, não há justificativa, por exemplo, para que um aluno de EJA custe menos que um aluno do ensino fundamental, a não ser que se tenha como objetivo oferecerIhe uma educação de baixa qualidade. (PINTO, 2007, p. 892).
\end{abstract}

Diante do exposto pelo autor, verifica-se que o Estado ainda não se dispôs a realizar estudo para se chegar a parâmetros mais coerentes com a realidade de cada região do país, a fim de estabelecer a distribuição dos recursos do fundo tendo em vista as assimetrias regionais. Por isso, apesar de se estabelecerem novos coeficientes que ampliaram a distribuição dos recursos em relação ao FUNDEF, ainda não foram suficientes para corrigir as distorções entre Norte e Sul do país. Nessa perspectiva, conforme os critérios de distribuição dos recursos do fundo, 1 (um) aluno do campo das séries iniciais em uma escola do Marajó tem o mesmo peso que 1 (um) aluno de uma escola na região Sul do país. Entretanto, as realidades geográficas e sociais são totalmente antagônicas.

Logo, apesar dos avanços, os critérios estabelecidos não representaram as condições ideais para a oferta de um ensino de qualidade, pois os procedimentos acordados, ao que se evidencia, interessavam à União, uma vez que a definição de critérios regionais poderia elevar sua contribuição aos fundos dos estados das regiões 
Norte e Nordeste, que são as que mais dependem financeiramente das transferências da União. Além disso, segundo Pinto (2007), é nessas regiões que estão situados os quatro Estados (MA, CE, AL e PA) onde o investimento por aluno é mínimo.

Para se chegar a um custo de cada modalidade de ensino em cada um dos estados, era preciso que fosse realizada, no entendimento de Bremaeker (2011), uma extensa pesquisa no país, sobretudo porque as assimetrias ainda são bastante fortes entre as regiões brasileiras, bem como entre o campo e a cidade. Para que o direito à educação ocorra em condições de igualdade, o custo por aluno deve ser resultado das diferenças das assimetrias regionais. Desse modo, é preciso avançar em cálculos que sejam mais coerentes com as realidades socioeconômicas dos Estados, como bem pontuou Bremaeker (2011). Portanto, as políticas educacionais para atenderem a população em condições de igualdade vão sempre exigir maior aporte de recursos financeiros do Estado.

Retomando as discussões do FUNDEB, importa destacar a intencionalidade do governo em ampliar os recursos e abrangência desse fundo, que passou a contemplar a Educação Infantil, a Educação de Jovens e Adultos, a Educação Especial e o Ensino Médio. Em relação aos recursos, ampliou-se para $20 \%$ o percentual da subvinculação dos impostos, além de ter acrescentado mais três impostos (IPVA, ITCD, ITR) ao fundo. Também a União passou a contribuir com 10\%, de forma efetiva, a partir do ano de 2010.

Entretanto, o incremento de recursos foi inferior ao de alunos incluídos, o que significa um valor aluno/ano menor. De acordo com Bremaeker (2011) e Pinto (2007), foram acrescentados $62,6 \%$ a mais de alunos em 2006 para serem contabilizados com os recursos do FUNDEB, porém, em termos de recursos para o fundo, os percentuais somaram apenas $37,3 \%$. Essa realidade trouxe consequências negativas aos estados e municípios, uma vez que tiveram de arcar com mais recursos do tesouro para manterem o padrão do atendimento nos moldes do FUNDEF.

Outro aspecto negativo para os municípios, relacionado ao FUNDEB, ocorreu, segundo Bremaeker (2011, p. 60), no processo da distribuição dos recursos do fundo, considerando que "[...] antes recebiam recursos estaduais para a manutenção dos alunos do ensino fundamental e que passaram a repartir os recursos com o financiamento do ensino médio". Essa situação ocorreu principalmente, em relação aos municípios de menor porte geográfico, tendo em vista que: 
Como estes municípios recebem em valores per capita um repasse maior de FPM e também de ICMS, as deduções dessas receitas para a constituição do fundo estadual do FUNDEB é relativamente elevada. Como eles possuem um pequeno número de alunos, o repasse dos recursos provenientes do fundo estadual - crédito do FUNDEB - é menor que a dedução, provocando um déficit nas suas contas. (BREMAEKER, 2011, p. 62).

Essas contradições, evidenciadas por Bremaeker (2011), acerca da captação e distribuição dos recursos dos fundos, em que uns perdem e outros ganham, têm sido uma das principais características dessa política, sem que se tenham estabelecido critérios para corrigir essas distorções. Por conseguinte, em meio a essas divergências, a EC n 53/2006 preconiza que "a União, os Estados, o Distrito Federal e os Municípios deverão assegurar, no financiamento da Educação Básica, a melhoria da qualidade de ensino, de forma a garantir padrão mínimo definido nacionalmente" (BRASIL, 2006, Art. 60, § 1, ADCT).

A questão que se apresenta é que, mediante o anúncio da qualidade do ensino, existe um hiato denominado insuficiência de recursos financeiros. Isso não é garantido nem mesmo pela política de fundos para garantir o atendimento educacional a todos os cidadãos nas mesmas condições de igualdade. Para Amaral (2012, p. 29), "o Brasil está entre os países que possuem maiores dificuldades para resolver os grandes desafios educacionais de sua população [...]", por causa da falta de recursos que correspondam às demandas educacionais.

Em detrimento desse aspecto, desde a elaboração do PNE, que vigorou entre 2001 e 2010 (Lei o 10.172/2001), tem sido pautada a elevação dos gastos públicos em educação, referentes ao percentual do PIB. Mesmo tendo sido aprovado pelo Congresso Nacional um percentual de $7 \%$, foi vetado pelo Presidente da República à época, o senhor Fernando Henrique Cardoso. O plano foi encerrado e o veto nunca mais voltou a ser discutido no congresso (CRUZ, 2011; AMARAL, 2012).

Amaral (2012) pontua que, ao final do PNE, a relação dos recursos da educação com o PIB voltou a ser discutida. Com isso, ganhou novos contornos, com a aprovação da EC no 59/09 garantindo que na aprovação dos próximos planos de educação fosse obrigatório assegurar a relação de um percentual do PIB com a educação. Tal proposição foi garantida pela Lei 13.005/2014, que aprovou o novo PNE e assegurou, na meta 20: "ampliar o investimento público em educação pública de forma a atingir, no $5^{\circ}$ ano de vigência dessa lei no mínimo, o patamar de $7 \%$ do PIB 
do País e, no mínimo, o equivalente a $10 \%$ do PIB ao final do decênio" (BRASIL, 2014).

Há de se recordar que a base estrutural que garante o financiamento da educação no Brasil está assentada, em sua maior parte, no recolhimento dos impostos vinculados à educação e nas contribuições sociais das empresas, expressas no salário-educação. Por isso, o fato de que a política de fundos, apesar de sua importância, principalmente por assegurar que $60 \%$ dos recursos devem ser aplicados em MDE, não se configura como uma política de financiamento da educação. Até porque ela não agrega novas receitas à educação, apenas fazendo a distribuição de recursos ao subvincular receitas de impostos que, por lei, pertenciam aos Estados, ao Distrito Federal e aos Municípios.

Diante do que se apresenta, verifica-se uma dicotomia entre o direito à educação, assegurado constitucionalmente com seus custos diferenciados em cada realidade dos municípios brasileiros, e o que se tem disponível para gastar, sempre inferior à demanda educacional, pois "[...] o limite em assegurar o direito à educação passa também pelo quantitativo de recursos disponibilizados" (GEMAQUE, 2011, p. 110). No entanto, a conta que se tem de fazer para garantir o direito à educação deve ser invertida, ou seja, não do que se tem disponível, mas do quanto se precisa.

Por fim, a atual estrutura de financiamento da educação, mesmo tendo ampliado os gastos, como destaca Castro (2014), dispõe de recursos insuficientes para financiar as políticas educacionais de interesse social com as melhorias substantivas, ou seja, que representem a ampliação do acesso aliado à qualidade social da educação.

\section{O efeito perverso do financiamento da educação para a garantia do direito a educação nos municípios}

Nos últimos anos, a sociedade obteve um conjunto de conquistas no que se refere ao direito à educação, mas, contraditoriamente, os investimentos ficaram sob a responsabilidade dos municípios. A exemplo, a ampliação do Ensino Fundamental para nove anos (dos 6 aos 14 anos), por meio da Lei $n$ ำ11.274/2006 (BRASIL, 2006), e em 2009, a obrigatoriedade da oferta de ensino a partir dos 4 anos de idade, com a aprovação da EC no 59/2009 (BRASIL, 2009). 
Com isso, foram atribuídas mais responsabilidades aos municípios, com implicações circunstanciais no campo do direito à educação. Cabe destacar que as municipalidades vinham assumindo matrículas de alunos de faixas etárias de 4 a 6 anos, porém, de forma facultativa; com a aprovação das legislações, a oferta passou a ser obrigatória. Diante do exposto, não cabe contestar a textualidade da lei, dada sua importância como conquista social que representou para a sociedade, principalmente para as camadas mais pobres da população. Com efeito, Alves e Pinto (2011) enfatizam:

[...] que a ampliação da obrigatoriedade é um importante avanço no que se refere ao direito à educação, sobretudo diante das evidências de que a obrigatoriedade tem promovido uma redução das desigualdades educacionais nos níveis de ensino obrigatórios - pelo menos no que se refere ao acesso - nos países que adotaram tal estratégia (ALVES; PINTO, 2011, p. 127).

Observa-se o mesmo entendimento e compreensão dos autores sobre os benefícios sociais que a ampliação do direito à educação, de forma obrigatória, representa para as populações menos favorecidas. Para Alves e Pinto (2011), apesar de o acesso à escola ter sido garantido, a qualidade tem ficado a desejar; assim sendo,

se esse critério não for considerado no processo de expansão, poderá causar uma 'inclusão excludente' ou apenas uma inclusão quantitativa, que não garantiria os resultados educacionais esperados para os indivíduos e, consequentemente, para o país (ALVES; PINTO, 2011, p. 148).

Todavia, apesar da importância dessa conquista social, esse processo não se fez acompanhar de novas fontes de recursos para a educação, não ampliando, por conseguinte, o valor aluno/ano que recebem da distribuição do FUNDEB e das demais receitas de impostos previstas constitucionalmente.

Contraditoriamente, o ente da federação que menos arrecada imposto na estrutura tributária do país é o que vem assumindo, nos últimos anos, mais responsabilidades com a oferta do ensino obrigatório (de 4 a 14 anos). Como pontuam Ednir e Bassi (2009), as regras constitucionais definem que o maior arrecadador seja o governo federal, seguido dos Estados e, por último, os municípios.

Por essa ótica, considerando também as inúmeras demandas sociais que cada município acumula sob sua responsabilidade, depreende-se que as regras do jogo 
são desiguais. Tomando por base as regras constitucionais em vigor no país, Ednir e Bassi (2009) exemplificam os percentuais de tributos que as três esferas de governo arrecadaram no ano de 2005: a união arrecadou $68,4 \%$, o conjunto dos estados $26 \%$ e o conjunto dos municípios 5,6\%. Mesmo após a União realizar as transferências de parte dos tributos a Estados e Municípios, e os Estados, aos municípios, as desigualdades ainda persistem. Ao final, a União continua centralizando $57,6 \%$ dos recursos, os estados $25,2 \%$ e os municípios, 17,2\%. (EDNIR; BASSI, 2009).

Observa-se, portanto, o nível de desigualdade que há entre as esferas de governo na arrecadação dos tributos, sendo a participação dos municípios (5,6\%) inexpressiva diante do total. No entanto, é onde se efetivam as principias políticas na área da saúde, assistência social, educação, meio ambiente, saneamento básico, entre outras (EDNIR; BASSI, 2009). Contraditoriamente, apesar de terem a menor arrecadação, são os municípios que têm as maiores responsabilidades na garantia do direito à educação obrigatória.

Essa realidade desigual sobre a partilha dos impostos torna os municípios dependentes das receitas de transferência da União, como a do Fundo de Participação dos Munícipios (FPM). Além do mais, como destacaram Ednir e Bassi (2009), os gestores locais, em função disso, tornaram-se reféns dos governos estaduais e federal, na busca de mais recursos para complementar suas receitas, a fim de investirem em políticas públicas em favor da população.

As responsabilidades pelas políticas educacionais, a fim de assegurar o direito à educação para as populações locais, têm se apresentado, nesse cenário, como um dos maiores desafios aos municípios. Desde a aprovação da LDB (9.394/1996), a constituição da política de fundos (FUNDEF/FUNDEB) e a aprovação da EC nำ59, uma série de políticas têm-se concentrado sob a tutela municipal. Essas ações do governo federal, para Castro (2011), tiveram como função estabelecer novos mecanismos de gestão; critérios técnicos sobre a alocação dos recursos financeiros da educação, para induzir a descentralização institucional e financeira das ações, bem como para criar mecanismos de avaliação dos sistemas de ensino.

Esse conjunto de medidas, todas efetivas com maior ou menor intensidade, serviu para fortalecer o papel coordenador e articulador do governo federal no gerenciamento do ensino e, posteriormente, de toda a Educação Básica (CASTRO, 2011). Mas, as responsabilidades pela oferta educacional ficam a cargo dos municípios e vêm crescendo anualmente, desde as atribuições, conferidas pela LDB 
9.394/1996, pela oferta do Ensino Fundamental e da Educação Infantil, e ainda se somam a isso a EJA e a Educação Especial. Os efeitos desse processo são expressos na evolução de matrícula nas redes municipais de ensino, no aumento do número de estabelecimentos, no transporte escolar, nos profissionais da educação, dentre outras responsabilidades.

No que diz respeito à evolução de matrículas, Pinto (2007) demonstra que, no ano de 1991, as redes municipais de ensino eram responsáveis por 37\% das matrículas públicas, quando, em 2006, chegaram a 52\%. Em contrapartida, em 1991, as redes estaduais concentravam $55 \%$ das matrículas desse nível de ensino, reduzindo para $40 \%$, em 2006, redução de 15 pontos percentuais nesse período.

Outro dado que evidencia como as responsabilidades educacionais dos municípios tem crescido de forma circunstancial é a evolução do número de funções docentes nas redes municipais de ensino em relação às redes estaduais. De acordo com as informações do Censo Escolar de 2006, do total de funções docentes que atuavam nas redes públicas (federal, estadual e municipal), cerca de 50\% pertenciam às redes estaduais de ensino e $34 \%$, às redes municipais. Contudo, no ano de 2014 , enquanto os Estados possuíam 36\% do total de funções docentes atuando em suas redes de ensino, os municípios já contavam com um índice de $63 \%$, ou seja, um acréscimo, em termos percentuais, de $29 \%$ para o período (MEC/INEP, 2006; 2014). Isso é mais uma evidência de que as mudanças das políticas educacionais do governo federal têm atribuído bem mais responsabilidades aos municípios.

Soma-se a isso o fato de a EC no 53/2006 ter determinado a criação do piso salarial profissional nacional para os profissionais do magistério público da Educação Básica; com isso, alguns municípios, para se adequarem às determinações da lei, aumentaram suas receitas para fazer frente ao gasto de pessoal. (CASTRO, 2011). Observa-se, assim, que uma série de demandas educacionais tem sido incorporada aos municípios - todas justas, do ponto de vista do direito à educação, porém, todas demandando recursos. Ao que tudo indica, essas variáveis - salários dos professores, ampliação do ensino fundamental de oito para nove anos; obrigatoriedade da oferta da educação a partir dos quatro anos de idade - foram subestimadas no cálculo de quanto isso representaria em termos de investimentos educacionais.

Consequentemente, a premissa da política de fundo, como expressa na EC no 53 , de garantir a equalização de oportunidades educacionais e o padrão mínimo de qualidade da educação escolar, tem sido comprometida. Tal fato é resultado de uma 
alta demanda educacional aos municípios com base em uma distribuição de recursos no valor aluno/ano sem as condições de promover o ensino de qualidade (PINTO, 2007).

Avalia-se, nesse contexto, que a instituição da política de fundo pela União, mesmo tendo ampliado sua participação com o FUNDEB, em termos de recursos aos Estados e Municípios, não foi suficiente para equalizar as oportunidades educacionais oferecidas às populações entre as regiões do país. Destaca-se, ainda, que a obrigatoriedade da pré-escola impôs novamente aos municípios uma readequação em suas redes de ensino para acolher essa nova clientela de estudantes, ou seja,

[...] além do investimento financeiro na melhoria da infraestrutura educacional das redes de ensino - o que passa pelo aumento da capacidade instalada para gerar novas vagas, pela melhora dos prédios, investimento em materiais e equipamentos, formação de professores e melhoria das condições de trabalho dos profissionais da educação -, o enfrentamento de questões sociais históricas, como a discriminação racial, o conflito urbano/rural, as disparidades do federalismo fiscal brasileiro e a superação dos problemas específicos da oferta de ensino em cada etapa de escolarização contemplada pela emenda. (ALVES; PINTO, 2011, p. 147-148).

Compartilha-se do mesmo entendimento desses autores de que a adoção dessas medidas é fundamental para que esse direito à escola se efetive de maneira satisfatória. São ações que demandariam recursos adicionais aos municípios, principalmente os que são dependentes de verbas de transferências da União.

Essa nova inclusão obrigatória se soma ao que Pinto (2007, p. 881) alertava no processo de implantação do FUNDEB, que o aumento da participação municipal nas matrículas da educação romperia "[...] o equilíbrio entre os alunos atendidos e a capacidade financeira dos municípios", porque, explica o autor, as municipalidades ficariam com mais matrículas do que os Estados. Em contrapartida, as receitas líquidas de impostos dos municípios seriam cerca de três quartos inferiores à obtida pelos Estados. Essa condição desigual na participação dos tributos entre os entes da federação, nas palavras do autor, "demostra uma situação de grande fragilidade do atual sistema de financiamento" da educação (PINTO, 2007, p. 881).

Contraditoriamente, a União, ente com maior capacidade de captação de recursos e que concentra mais da metade dos impostos recolhidos, como apontaram os estudos de Ednir e Bassi (2009), tem contribuído de forma insuficiente com os municípios de baixa capacidade financeira para que estes ampliem seus 
investimentos com educação, principalmente os que ficam nas regiões Norte e Nordeste. Por isso, o pacto federativo e o regime de colaboração têm que avançar em termos das responsabilidades financeiras, a fim de diminuir as assimetrias regionais.

\section{Considerações finais}

As análises aqui apresentadas evidenciaram que 0 avanço das conquistas sociais em relação ao direito à educação de forma obrigatória, foram extremamente importantes à sociedade. Entretanto, as atribuições em garantir essas conquistas ficaram sob a responsabilidade apenas dos municípios, de forma direta, apesar da justificativa de que, por meio dos fundos educacionais, a União esteja exercendo seu papel de colaboradora. Entretanto, são recursos insuficientes, que inviabilizam a educação de qualidade.

Portanto, as bases do financiamento da educação para assegurar o direito à educação nas municipalidades não correspondem às necessidades. $\mathrm{Na}$ ampliação da oferta da educação básica, os dados evidenciaram que os municípios têm assumido maiores responsabilidades em relação aos demais entes da federação. Outra questão analisada diz respeito à contradição existente entre os discursos que apregoaram a ampliação dos recursos para a educação e a não alteração da matriz do financiamento. Com isso, a ampliação dos recursos tem ocorrido, mas não na mesma proporção que a inclusão de matrículas nas redes educacionais públicas.

Apesar de apresentar pontos negativos, a política de fundo possui pontos positivos, entre eles o estabelecimento do valor aluno/ano, o fato de as matrículas serem referência para calcular quanto cada rede de ensino deve receber. Verificouse, no entanto, que embora o acesso à educação tenha crescido, os recursos não cresceram na mesma proporção.

Por fim, é notório os limites e os efeitos do financiamento da educação para os municípios, tendo em vista que, nos últimos anos, tem sido atribuída a eles uma série de responsabilidades. Por outro lado, verificou-se que o ente da federação que menos arrecada impostos é o que menos recebe das transferências, por isso, os municípios, principalmente os mais pobres, têm sérios limites para financiar suas políticas educacionais e responder à população com políticas satisfatórias. 


\section{Referências}

ALVES, T.; PINTO, J. M. de R. Quem serão os potenciais ingressantes na educação básica brasileira com a ampliação da obrigatoriedade escolar? In: GOUVEIA, A. B.; PINTO, J. M. de R.; CORBUCCI, P. R. (Orgs.). Federalismo e políticas educacionais na efetivação do direito à educação no Brasil. Brasília, DF: Ipea, 2011. Disponível em: $<$ http://www.ipea.gov.br/portal/images/stories/PDFs/livros/livros/livro_federalis mopoliticas.pdf>. Acesso em: 15 de mai de 2020.

AMARAL, N. C. Para compreender o financiamento da educação básica no Brasil. Brasília, DF: Liber, 2012.

BREMAEKER, F. E. J. de. A política de fundos para a educação e o impacto nas finanças dos estados e dos municípios. In: GOUVEIA, A. B.; PINTO, J. M. de R.; CORBUCCI, P. R. (Orgs.). Federalismo e políticas educacionais na efetivação do direito à educação no Brasil. Brasília, DF: Ipea, 2011. Disponível em: <http://www.ipea.gov.br/portal/images/stories/PDFs/livros/livros/livro_federalismopolit icas.pdf>. Acesso em: 15 de mai de 2020.

BRASIL. Lei no 8.069, de 13 de julho de 1990. Dispõe sobre o Estatuto da Criança e do Adolescente, e dá outras providências. Coleção de Leis do Brasil, Brasília, DF, v. 4, p. 2379, 1990. Disponível em: <http://www2.camara.leg.br/legin/fed/lei/1990/lei8069-13-julho-1990-372211-norma-pl.html>. Acesso em 08 de mai de 2020.

Lei no 9.394, de 20 de dezembro de 1996 (LDB). Estabelece as diretrizes e bases da educação nacional. Diário Oficial [da] República Federativa do Brasil, Poder Executivo, Brasília, DF, 23 dez. 1996. Disponível em: <http://www.planalto.gov.br/CCIVIL_03/ leis/L9394.htm>. Acesso em: 18 de mai de 2020.

Constituição da República Federativa do Brasil (1988). Diário Oficial [da] República Federativa do Brasil, Poder Executivo, Brasília, DF, 5 out. 1988. Disponível em: <http://www.planalto.gov.br/ccivil_03/Constituicao/Constituicao.htm>. Acesso em: 13 de mai de 2020.

Emenda Constitucional no 14, de 12 de setembro de 1996. Modifica os Arts. 34, 208, 211 e 212 da Constituição Federal de dá nova redação ao Art. 60 do ato das disposições constitucionais transitórias. Diário Oficial [da] República Federativa do Brasil, Poder Executivo, Brasília, DF, 13 set. 1996. Disponível em: <http://www.planalto.gov.br/ccivil_03/Constituicao/ Emendas/Emc/emc14.htm>. Acesso em: 20 de mai de 2020.

. Lei № 9.424, de 24 de dezembro de 1996. Dispõe sobre o Fundo de Manutenção e Desenvolvimento do Ensino Fundamental e de Valorização do Magistério, na forma prevista no art. 60, $\S 7^{\circ}$, do Ato das Disposições Constitucionais Transitórias, e dá outras providências. Diário Oficial [da] República Federativa do Brasil, Poder Executivo, Brasília, DF, 26 dez. 1996. Disponível em: 
<http://www.planalto.gov.br/CCIVIL_03/ leis/L9424.htm>. Acesso em: 12 abr. 2012. Acesso em: 16 de mai de 2020.

Lei $\mathrm{n}$ - 10.172, de 9 de janeiro de 2001. Aprova o Plano Nacional de Educação e dá outras providências. Diário Oficial [da] República Federativa do Brasil, Poder Executivo, Brasília, DF, 10 jan. 2001. Disponível em: http://www.planalto.gov.br/ccivil_03/leis/leis_2001//10172.htm. Acesso em: 17 de mai de 2020.

. Lei no 11.274, de 6 de fevereiro de 2006. Altera a redação dos arts. 29, 30, 32 e 87 da Lei no 9.394, de 20 de dezembro de 1996, que estabelece as diretrizes e bases da educação nacional, dispondo sobre a duração de 9 (nove) anos para o ensino fundamental, com matrícula obrigatória a partir dos 6 (seis) anos de idade. Diário Oficial [da] República Federativa do Brasil, Poder Executivo, Brasília, DF, 7 fev. 2006. Disponível em: <http://www.planalto.gov.br/ccivil_ 03/_Ato20042006/2006/Lei/l11274.htm>. Acesso em: 09 de mai de 2020.

Emenda Constitucional no 53, de 19 de dezembro de 2006. Dá nova redação aos arts. $7^{\circ}, 23,30,206,208,211$ e 212 da Constituição Federal e ao art. 60 do Ato das Disposições Constitucionais Transitórias. Diário Oficial [da] República Federativa do Brasil, Poder Executivo, Brasília, DF, 20 dez. 2006. Disponível em: <http://www.planalto.gov.br/ccivil_03/_Constituicao/Emendas/Emc/emc53.htm>. Acesso em: 09 de mai de 2020.

Lei № 11.494, de 20 de junho de 2007. Regulamenta o Fundo de Manutenção e Desenvolvimento da Educação Básica e de Valorização dos Profissionais da Educação - FUNDEB, de que trata o art. 60 do Ato das Disposições Constitucionais Transitórias; altera a Lei no 10.195, de 14 de fevereiro de 2001; revoga dispositivos das Leis nos 9.424, de 24 de dezembro de 1996, 10.880, de 9 de junho de 2004, e 10.845, de 5 de março de 2004; e dá outras providências. Diário Oficial [da] República Federativa do Brasil, Poder Executivo, Brasília, DF, 22 jun. 2007. Disponível em: <http://www.planalto.gov.br/ccivil_03/_ato2007-2010/2007/ lei//11494.htm>. Acesso em: 09 de mai de 2020.

Emenda Constitucional no 59, de 11 de novembro de 2009. Diário Oficial [da] República Federativa do Brasil, Poder Executivo, Brasília, DF, 12 nov. 2009. Disponível em: <http://www.planalto.gov.br/ccivil_03/Constituicao/Emendas/Emc/emc59.htm>, Acesso em: 09 de mai de 2020.

. Lei no 13.005, de 25 de junho de 2014. Aprova o Plano Nacional de Educação - PNE e dá outras providências. Diário Oficial [da] República Federativa do Brasil, Poder Executivo, Brasília, DF, 26 jun. 2014. Disponível em: $<$ http://www.planalto.gov.br/ccivil_03/_ato2011-2014/2014/lei//13005.htm>. Acesso em: 09 de ami de 2020.

CASTRO, A. M. D. A.. Gerencialismo e Educação: estratégias de controle e regulação da gestão escolar. In: CABRAL NETO, A. et al. (Orgs.). Pontos e contrapontos da política educacional: uma leitura contextualizada de iniciativas governamentais. Brasília, DF: Líber Livro Editora, 2007. p. 115-144. 
CASTRO, J. A. de. Financiamento e gasto público na educação básica no Brasil: 1995-2005. Educação \& Sociedade, Campinas, v. 28, n. 100. Edição Especial, p. 857876, out. 2007. Disponível em: <http://www.scielo.br/pdf/es/v28n100/a1128100.pdf>. Acesso em: 10 de mai de 2020.

Financiamento da educação pública no Brasil: evolução dos gastos. GOUVEIA, A. B.; PINTO, J. M. de R.; CORBUCCI, P. R. (Orgs.). Federalismo e políticas educacionais na efetivação do direito à educação no Brasil. Brasília, DF: Ipea, 2011. Disponível em: $<$ http://www.ipea.gov.br/portal/images/stories/PDFs/livros/livros/livro_federalismopolit icas. pdf $>$. Acesso em: 15 de mai de 2020.

Dilemas para o financiamento da educação. In: CUNHA, C. da; GADOTTI, M.; NOGUEIRA, F. O Sistema Nacional de Educação: diversos olhares $\mathbf{8 0}$ anos após o Manifesto. Brasília, DF: MEC/SASE, 2014.

CRUZ, R. E. da. Federalismo e financiamento da educação: a política do FNDE em debate? In: GOUVEIA, A. B.; PINTO, J. M. de R.; CORBUCCI, P. R. (Orgs). Federalismo e políticas educacionais na efetivação do direito à educação no Brasil. Brasília, DF: Ipea, 2011. Disponível em: $<$ http://www.ipea.gov.br/portal/images/stories/

PDFs/livros/livros/livro_federalismopoliticas.pdf>. Acesso em: 15 de mai de 2020.

EDINIR, M.; BASSI, M. Bicho de Sete Cabeças: para entender o financiamento da educação brasileira. São Paulo: Petrópolis, Ação Educativa, 2009.

GOUVEIA. A. B.; POLENA, A. Financiamento da educação e indicadores de qualidade: um estudo exploratório de seis municípios brasileiros. Revista Brasileira de Política e Administração da Educação, v. 31, n. 2, p. 255-273 mai./ago. 2015. Disponível em: <http://seer.ufrgs.br/index.php/rbpae/article/view/61727/36488>. Acesso em: 12 de mai de 2020.

GEMAQUE, R. M. O. Políticas de financiamento e direito à educação básica: o Fundef e o Fundeb. SER Social, Brasília, v. 13, n. 29, p. 90-112, jul./dez. 2011. Disponível em: <http://periodicos.unb.br/index.php/SER_Social/article/view/6355>. Acesso em: 05 de ami de 2020.

INEP. Instituto Nacional de Estudos e Pesquisas Educacionais Anísio Teixeira. Censo Escolar da Educação Básica 2018: resumo técnico / Instituto Nacional de Estudos e Pesquisas Educacionais Anísio Teixeira. Brasília, DF: O Instituto, 2018. Disponível em:

$<$ http://download.inep.gov.br/educacao basica/censo escolar/resumos tecnicos/res umo tecnico censo educacao basica 2018.pdf>. Acesso em: 18 de mai de 2020.

PINTO, J. M. A política recente de fundos para o financiamento da educação e seus efeitos no pacto federativo. Educação e Sociedade, Campinas, v. 28, n. 100. Edição Especial, p. 877-897, out. 2007. Disponível em: <http://www.scielo.br/pdf/es/v28n100/a1228100.pdf>. Acesso em: 13 de mai de 2020. 
REZENDE PINTO, I. R. de. A garantia do direito à educação de crianças e adolescentes pela via judicial: análise das decisões judiciais do Supremo Tribunal Federal (2003-2012). 2014. 215 f. Dissertação (Mestrado em Educação) Universidade Federal da Grande Dourado. Dourados, MS.

SENA, P. O Financiamento da Educação de Qualidade. Revista Educação e Políticas em Debate, v. 3, n. 2, ago./dez. 2014. Disponível em: <http://www.seer.ufu.br/index.php/revista educaopoliticas/article/view/30280>; Acesso em: 10 de mai de 2020.

SHIROMA, E. O. et al. (Orgs.). Política Educacional. Rio de Janeiro: DP\&A, 2000. 